\title{
More bark than bite? The role of livestock guarding dogs in predator control on Namibian farmlands
}

\author{
Gail C. Potgieter, Graham I. H. Kerley and Laurie L. Marker
}

\begin{abstract}
The conflict between predators and livestock farmers is a threat to carnivore conservation. Livestock guarding dogs are promoted as a non-lethal, environmentally friendly method to mitigate this conflict. As part of a farmer-carnivore conflict mitigation programme, the Cheetah Conservation Fund breeds Anatolian shepherd (also known as Kangal) dogs to protect livestock from predators. During 2009-2010 we interviewed 53 commercial and 20 subsistence Namibian farmers that are using 83 such dogs. Fewer commercial and subsistence farmers reported livestock losses to predators during the most recent year of guarding-dog use compared to the year before dogs were introduced. All subsistence farmers, but not all commercial farmers, ceased killing predators during the most recent year of guarding-dog use. All farmers ceased killing cheetah Acinonyx jubatus and leopard Panthera pardus during this year, and one dog killed a single cheetah. Conversely, dogs and farmers killed more black-backed jackals Canis mesomelas between them in the survey year than the farmers reported killing in the year before acquiring dogs. Two of the dogs reportedly killed non-target carnivore species, and 15 killed prey species. Thus our results challenge the categorization of livestock guarding dogs as a non-lethal conflict mitigation method. We suggest that the conservation status and body size of wild carnivores relative to the size of the guarding dogs be considered before introducing dogs to protect livestock. Additionally, corrective training for dogs that chase or kill non-target species should be implemented, especially where farmers value these species or where non-target species are threatened.
\end{abstract}

Keywords Farmer-predator conflict, human-wildlife conflict, lethal control, livestock guarding dogs, livestock losses, Namibia, non-lethal control

To view supplementary material for this article, please visit http://dx.doi.org/10.1017/So030605315000113

\footnotetext{
Gail C. Potgieter ${ }^{*}$ (Corresponding author) and Graham I. H. Kerley Department of Zoology, Centre for African Conservation Ecology, Nelson Mandela Metropolitan University, South Africa. E-mail gailsfelines@gmail.com

LaURIE L. Marker Cheetah Conservation Fund, Namibia

${ }^{*}$ Also at: Cheetah Conservation Fund, Namibia

Received 27 October 2014. Revision requested 4 December 2014. Accepted 20 January 2015. First published online 20 May 2015.
}

\section{Introduction}

Conto onflict between humans and carnivores is an ancient, global phenomenon that arises when carnivores and humans compete for space and prey species, or humans are threatened. Human-carnivore conflicts occur most commonly when carnivores prey on domesticated livestock, and farmers respond by killing carnivores (Sillero-Zubiri \& Laurenson, 2001; Woodroffe et al., 2005). During the last century the existential, economic and ecological values of carnivores have been emphasized, providing impetus for carnivore conservation (Miller et al., 2001; Ripple et al., 2014). Mitigating farmer-carnivore conflict is thus a key component of carnivore, and hence biodiversity, conservation (Treves \& Karanth, 2003; Breitenmoser et al., 2005). Although conflict mitigation ultimately relies on addressing the competing human interests of livestock farming and carnivore conservation (Madden \& McQuinn, 2014; Redpath et al., 2015), efforts by conservationists to reduce actual and perceived livestock losses by farmers play a key role in improving relationships between these stakeholders.

Methods used to reduce livestock depredation are of two types: lethal and non-lethal control. Large-scale lethal control using indiscriminate methods such as poisoning, snaring and hunting can be environmentally damaging and are increasingly socially unacceptable (Treves \& NaughtonTreves, 2005). Furthermore, the removal of carnivores can have unpredictable negative ecological consequences because of the complex roles carnivores play in food webs (Treves \& Naughton-Treves, 2005; Ripple et al., 2014). However, selective lethal control methods (e.g. trapping by trained personnel) can sometimes reduce livestock depredation and subsequently increase farmers' tolerance of carnivores (Treves \& Naughton-Treves, 2005; Bangs et al., 2006).

Attention has turned towards non-lethal, environmentally friendly methods of mitigating farmer-carnivore conflict (Breitenmoser et al., 2005; Gehring et al., 2006; Shivik, 2006). Livestock guarding dogs are promoted as one such method of mitigating conflict and thus conserving large carnivores (Marker et al., 2005; Gehring et al., 2010; Urbigkit \& Urbigkit, 2010; Rigg et al., 2011; van Bommel \& Johnson, 2012; McManus et al., 2014). This, however, relies on the following assumptions: (1) if guarding dogs reduce livestock losses, fewer carnivores will be killed by farmers; (2) guarding dogs do not kill target species; (3) guarding dogs do not kill non-target species. 
In Namibia most guarding dogs placed on farms by the Cheetah Conservation Fund have reduced livestock losses (Marker et al., 2005; Potgieter et al., 2013). This is similar to results for other countries where guarding dogs have been introduced or studied as a traditional means of protecting livestock (Rigg et al., 2011; van Bommel \& Johnson, 2012; McManus et al., 2014). However, there are many examples of differences in farmers' attitudes and their behaviour towards carnivores, and livestock losses may not be an accurate predictor of carnivore killing by farmers (Marker et al., 2003; Treves \& Karanth, 2003; Selebatso et al., 2008; Thorn et al., 2012). Furthermore, commercial and subsistence farmers differ in terms of their tolerance of carnivores, and their propensity to kill carnivores on their farms (Marker et al., 2003; Romañach et al., 2007; Inskip \& Zimmermann, 2009). Consequently, although livestock guarding dogs may reduce livestock losses, they may not cause farmers to abandon lethal control methods. The first question addressed in this study was whether the use of livestock guarding dogs changed the behaviour of commercial and subsistence farmers towards carnivores in Namibia.

Historically, Namibian farmers have removed the largest-bodied predators, lion Panthera leo and spotted hyaena Crocuta crocuta. However, cheetah Acinonyx jubatus (21-64 kg) and leopard Panthera pardus (17-90 kg) persist in most areas and have thus assumed apex predator roles (Marker-Kraus et al., 1996; mass ranges from Hunter \& Barrett, 2011). These two species are protected under Namibian law, although it is legal to kill them in defence of human life or livestock (Ministry of Environment and Tourism, 1975). In contrast, black-backed jackal Canis mesomelas $(6-11 \mathrm{~kg})$ and caracal Caracal caracal $(6-26 \mathrm{~kg})$ are mesopredators that are not protected by law, occur widely throughout southern Africa, and are killed in high numbers (Skinner \& Chimimba, 2005; Stadler, 2006). Leopard, cheetah, caracal and black-backed jackal are the most commonly reported species to cause sheep and goat losses in southern Africa (Marker et al., 2003; Balme et al., 2009; Thorn et al., 2012), and were thus categorized as target predators in our study. Other species capable of killing livestock in our study area (domestic dogs and baboons) were included as target predators when killed by livestock guarding dogs, but farmers were not asked whether they had killed these species.

Anatolian shepherd (also known as Kangal) dogs are large-breed livestock guarding dogs (adult mass 25-50 kg) that have the potential to act as introduced large carnivores. The Kangal dog, in particular, has been reported to kill wolves in Turkey and is thus recommended for protecting livestock against large carnivores (Urbigkit \& Urbigkit, 2010). Although there are anecdotal reports of guarding dogs fighting with and/or killing target predators (see Urbigkit \& Urbigkit, 2010, for a review), this is the first attempt at quantifying the number of target predators killed by guarding dogs. We compared interactions between livestock guarding dogs and target predator species with respect to their conservation status (protected or non-protected) and body size. Our second question therefore is whether livestock guarding dogs kill target predator species and, if so, how this relates to predator killing by farmers.

Non-target species may be small-bodied carnivores that do not prey on goats and sheep (e.g. African wildcat Felis silvestris, a non-protected carnivore that may prey on poultry, which were not guarded by the dogs in our study), or prey species such as wild ungulates. Livestock guarding dogs have been proposed as a non-lethal method for keeping potentially disease-transmitting ungulates away from livestock (Gehring et al., 2010). However, free-ranging domestic dogs (i.e. dogs that are not controlled; Vanak \& Gompper, 2009) can present a threat to ungulates by killing or harassing them (Young et al., 2011; Silva-Rodríguez \& Sieving, 2012). We questioned respondents about whether they had witnessed their dogs killing non-target species and, if so, how many animals they witnessed being killed. In the same questionnaire (Supplementary Material) respondents were asked whether their dogs exhibited behavioural problems, such as chasing wildlife. Although wildlife chasing by purebred guarding dogs has been studied previously (Marker et al., 2005; Gingold et al., 2009), surveys that ask explicitly whether these dogs kill non-target species, and how many animals they kill, have not been conducted (but see Sepúlveda et al., 2014, for mixed-breed guarding dogs). In Namibia farmers have the right to hunt common prey species occurring on their farms for meat and/or profit (Richardson, 1998; Naidoo et al., 2010). Consequently, farmers have negative views of dogs killing valuable wildlife. Our third question is whether livestock guarding dogs kill nontarget species.

Previously we have examined the use of livestock guarding dogs from the perspective of Namibian livestock farmers, thus confirming the role of these dogs in livestock protection (Potgieter et al., 2013). Here we aimed to evaluate the use of these dogs in terms of carnivore conservation, and more specifically to answer the above three questions. Importantly, these questions address the fundamental assumptions of the non-lethal role of guarding dogs, and identify potential unexpected consequences of management interventions.

\section{Study area}

Most of the livestock guarding dogs studied were placed on farms in the central region of Namibia (Fig. 1) through the Cheetah Conservation Fund's Anatolian shepherd breeding programme (see Marker et al., 2005, for details). This programme was initiated to reduce farmer-carnivore conflict in 


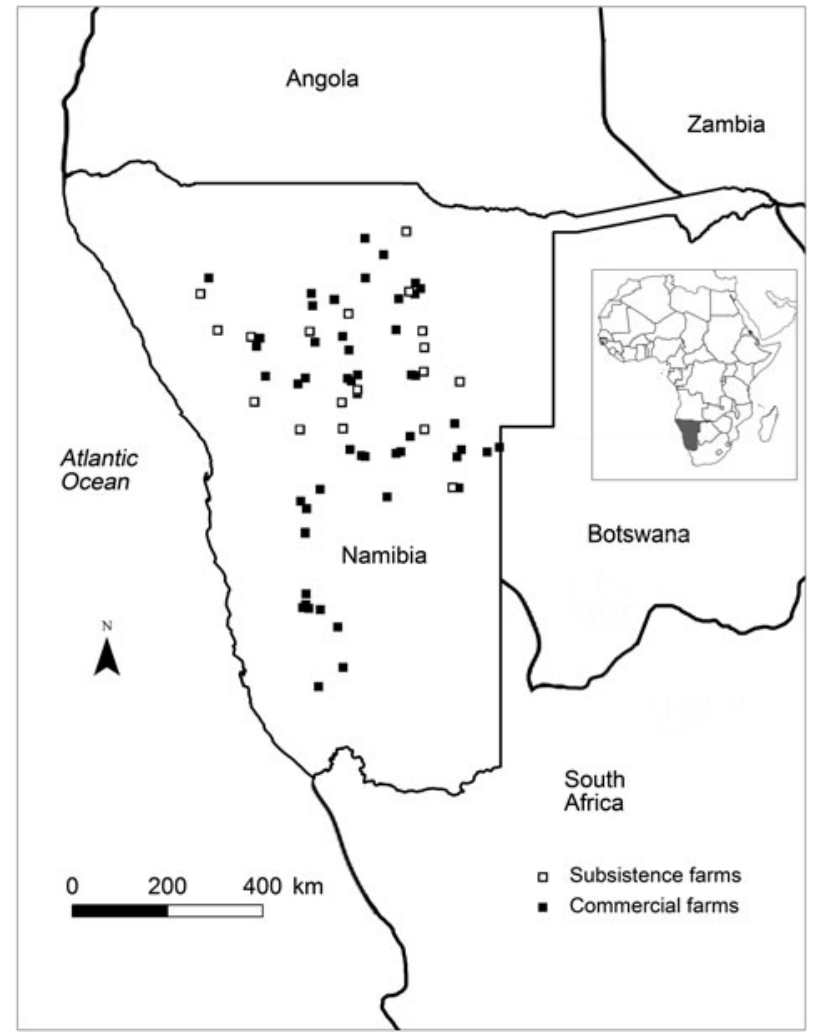

FIG. 1 Locations of subsistence and commercial farms in Namibia that received livestock guarding dogs via the Cheetah Conservation Fund. The shaded area on the inset indicates the location of Namibia in Africa.

Namibia, with particular emphasis on cheetah conservation (Marker et al., 2005). Consequently, dog placements were prioritized in the central region, which supports the core cheetah population in Namibia (Marker-Kraus et al., 1996).

The Cheetah Conservation Fund makes guarding dogs available to both commercial and subsistence farmers. The 83 dogs in this study belonged to 73 farmers $(53$ commercial and 20 subsistence). All of the commercial farmers owned their land (i.e. freehold farms), whereas the subsistence farmers were either on government-owned communal land (14) or resettlement farms (6). Resettlement farms are former freehold farms that were bought by the government and subdivided; farmers that lease these subdivisions from the government are known as resettled farmers (Odendaal, 2005). As resettled farmers lease only a portion of a fullsized commercial farm, they use their livestock as a means of subsisting rather than for commercial purposes (Odendaal, 2005). Consequently, we included resettled farmers in the subsistence farmer category.

Livestock farms in the central region of Namibia (Fig. 1) are either fenced with multiple-stranded stock fences (all commercial farms and resettled farms) or unfenced (communal farms). Fences are typically porous to wildlife, which are thus able to move freely within and between the farms.

\section{Methods}

All livestock guarding dogs were raised with livestock and placed with the flock they protected from 8 weeks of age, following established training methods (Lorenz \& Coppinger, 1996; Dawydiak \& Sims, 2004). None of the dogs were bred or placed for the purposes of this research. Each farmer who receives a dog signs a consent form that allows the Cheetah Conservation Fund to visit the farms regularly to evaluate the dogs, and confiscate dogs that are mistreated or malnourished.

Eighty-three guarding dogs $>6$ months of age (mean age $39 \pm$ SE 3.3 months) were assessed during March 2009September 2010 on routine farm visits. Seventy-three of the dogs were the only purebred guarding dogs working at their respective farms. Ten dogs were placed with farmers that had already received a dog from the Cheetah Conservation Fund. Six of these dogs did not guard the same livestock as the previously placed guarding dog but guarded other herds on the same farm. The other four dogs worked with the previously placed guarding dogs to guard the same herds.

All of the sheep and goats guarded by the dogs in this study $(\mathrm{n}=83)$ were herded into enclosures at night, and $67(81 \%)$ of the dogs worked with a herder during the day. The dogs were thus restricted to parts of the farms that were within walking distance of the night-time enclosures. Apart from two exceptional instances (one involving a cheetah, another a caracal), all of the reported incidents of dogs killing predators occurred during the day, outside the nighttime enclosures. Besides the four guarding dogs that worked with previously placed dogs, 54 (68\%) of the remaining dogs in the study had some interaction with other farm dogs. The farm dogs were usually small mixed-breed dogs belonging to the herders that worked with the purebred guarding dogs.

The farmers were contacted by telephone prior to our visits, to obtain permission to access their land; none refused permission to visit their farms or conduct interviews. Respondents (farm owners or farm employees working with the dogs) were interviewed using a standard questionnaire (Supplementary Material). Farmers that receive dogs from the Cheetah Conservation Fund are not required to cease killing predators (Marker et al., 2005). The respondents thus had little reason to respond dishonestly to the questions about farmers killing predators. Respondents were questioned regarding livestock loss and predator killing during the year prior to introducing their guarding dogs (hereafter, before the dog) and the year prior to the interview (hereafter, since the dog).

As the farmers' predator-killing strategies may have changed after receiving the first guarding dog, questions regarding predator killing by farmers were excluded for the 10 dogs placed on farms that had already received a dog from the programme. However, questions regarding livestock losses and the killing behaviour of the guarding dog were 
excluded only for the four dogs that were placed in the same herd as another guarding dog. Uncertain responses were treated as missing data, which reduced the sample size for some analyses as answers were required for questions relating to both before the dog and since the dog for inclusion in the paired analyses. Some respondents were certain their dog had killed particular species but could not give exact numbers killed; these responses were excluded from the analyses, to be conservative. Consequently the sample sizes varied for each of our analyses according to the number of respondents who were able to provide enough information for each question.

Non-target carnivores killed by livestock guarding dogs were categorized as those species that are not verified killers of sheep and goats. The prey species reportedly killed by the dogs were categorized according to their value to farmers. Among antelope species, springbok Antidorcas marsupialis and larger antelopes were considered more valuable. Common duiker Sylvicapra grimmia, smaller antelopes, and warthog Phacochoerus africanus were considered less valuable species. Mammals $<_{4} \mathrm{~kg}$ (e.g. hare, mongoose) were not included in our analysis, as encounters between the dogs and small mammals were less likely to be noticed by respondents. Cases of suspected wildlife killing were excluded, as the respondents could not be sure whether the dog was the killer, or which species had been killed. Given the distances between farms where the dogs were placed (Fig. 1) it was logistically impractical to verify reported killings. Consequently we relied on asking respondents questions about their reports to determine their certainty. If a respondent revealed some uncertainty about their answer we excluded it from our analyses.

All data were positively skewed and not normally distributed (Kolmogorov-Smirnov and Shapiro-Wilk tests, $\mathrm{P}<0.001)$. Wilcoxon signed-rank tests were therefore used for repeated measures with continuous data. Two-sided Fisher's exact tests were used for comparisons between related groups of categorical data. The data presented here are from all 73 farmers using purebred guarding dogs from the Cheetah Conservation Fund at the time of the study. Consequently, confidence intervals are not given for data quoted as percentages. McNemar's non-parametric test was used to compare the proportional data for livestock losses and predators killed before and since dogs were introduced. All statistical procedures were conducted using SPSS v. 20 (IBM, New York, USA) and only results where $\mathrm{P}<0.05$ were considered significant.

\section{Results}

Livestock guarding dogs and target predators

Fewer farmers reported livestock losses to all predators combined since the dogs compared to before the dogs
$(\mathrm{P}<0.001$, Table 1). Only reported losses to leopard on both types of farms were not reduced since the dogs $(\mathrm{P}=0.38$, Table 1$)$. Both commercial and subsistence farmers reported jackal as the most frequent cause of livestock losses. Fewer farmers reported losses to jackal since the dogs than before the dogs, on both types of farms $(\mathrm{P}<0.001$, Table 1). Fewer commercial farmers reported livestock losses to cheetah and caracal since the dogs compared to before the dogs $(\mathrm{P}=0.002$ and $\mathrm{P}=0.007$, respectively, Table 1). Similar proportions of commercial and subsistence farmers reported losses before $(\mathrm{P}=1.00)$ and since $(\mathrm{P}=1.00)$ dog introduction (Table 1$)$.

Of the 48 farmers that reportedly lost livestock before the introduction of livestock guarding dogs and whose predator-killing strategies were known, 31 (65\%) did not kill predators before the dogs were introduced. Furthermore, 20 ( $77 \%)$ of the 26 farmers that reported livestock losses since the dog did not kill predators. The jackal was the predator killed most frequently by both types of farmers (Table 1).

Combining the farm types, fewer farmers reported killing any of the target predator species since the dogs were introduced $(P=0.022$, Table 1). Similar proportions of commercial and subsistence farmers reportedly killed predators before the dogs were introduced $(P=1.00$, Table 1$)$. During the year after receiving the dogs none of the subsistence farmers killed predators but $12(26 \%)$ of the commercial farmers $(n=67)$ continued to kill predators $(P=0.013)$. A significant reduction in predator killing by farmers was found only for subsistence farmers killing all predators $(\mathrm{P}=0.031)$ and jackal only $(\mathrm{P}=0.031)$; the number of commercial farmers killing predators did not decrease significantly $(\mathrm{P}=0.45)$.

Farmers killed fewer predators since the dogs $(1.2 \pm \mathrm{SE}$ 0.63) than before the dogs (1.8 \pm SE 0.67; $z=-2.38$, $\mathrm{P}=0.017, \mathrm{n}=62$; Table 2). As most of the predators killed were jackals, a similar result was found for this species, but the reductions in farmers killing other predator species were not significant (Table 2). No cheetahs or leopards were killed by farmers since the dogs were introduced.

Forty-two of 79 dogs (53\%) reportedly killed target predator species. Thirty-seven dogs $(47 \%)$ reportedly killed jackals. Additionally, eight dogs (10\%) reportedly killed baboons, three ( $4 \%$ ) caracals, two (3\%) domestic dogs, and one (1\%) a cheetah. The presence of other mixed-breed working dogs did not affect whether or not the purebred guarding dogs killed predators $(\mathrm{P}=0.053)$ or non-target species $(\mathrm{P}=0.76)$.

Farmers and dogs combined killed more jackal (3.4 \pm SE 0.77 per farm per year) than the farmers alone before the dogs were introduced $(1.7 \pm \mathrm{SE} 0.68 ; z=-3.15, \mathrm{P}=0.002, \mathrm{n}=$ 61; Fig. 2a). Similarly, farmers alone killed $0.10 \pm$ SE 0.06 caracal per farm per year before the dogs were introduced, whereas farmers and dogs killed $0.19 \pm$ SE 0.10 caracal per 
TABLE 1 The number and proportion of commercial and subsistence farmers that reported livestock loss as a result of predation, and killing target carnivores, before and since the introduction of livestock guarding dogs.

\begin{tabular}{|c|c|c|c|c|c|c|c|}
\hline \multirow[b]{2}{*}{ Status } & \multirow[b]{2}{*}{ Farm type (n) } & \multicolumn{6}{|c|}{$\underline{\text { No. of predators }(\%)}$} \\
\hline & & All species & $\begin{array}{l}\text { Jackal } \\
\text { Canis mesomelas }\end{array}$ & $\begin{array}{l}\text { Cheetah } \\
\text { Acinonyx jubatus }\end{array}$ & $\begin{array}{l}\text { Caracal } \\
\text { Caracal caracal }\end{array}$ & $\begin{array}{l}\text { Leopard } \\
\text { Panthera pardus }\end{array}$ & $\begin{array}{l}\text { Baboon } \\
\text { Papio sp. }\end{array}$ \\
\hline \multicolumn{8}{|c|}{ Reported livestock losses } \\
\hline Before dog & All $(60)^{1}$ & $51(85)^{* *}$ & $42(70)^{* *}$ & $16(27)^{* *}$ & $15(25)^{* *}$ & $5(8)$ & $7(12)^{*}$ \\
\hline Since dog & All $(60)^{1}$ & $21(35)^{* *}$ & $16(27)^{* *}$ & $6(10)^{* *}$ & $4(7)^{* *}$ & $2(3)$ & $0(0)^{\star}$ \\
\hline Before dog & Commercial (44) & $37(84)^{* *}$ & $28(64)^{* *}$ & $14(32)^{* *}$ & $11(25)^{*}$ & $1(2)$ & $7(16)^{*}$ \\
\hline Since dog & Commercial (44) & $15(34)^{* *}$ & $10(23)^{* *}$ & $5(11)^{* *}$ & $3(7)^{*}$ & $1(2)$ & $0(0)^{\star}$ \\
\hline Before dog & Subsistence (16) & $14(88)^{* *}$ & $14(88)^{* *}$ & $2(13)$ & $4(25)$ & $4(25)$ & $0(0)$ \\
\hline Since dog & Subsistence (16) & $6(38)^{* *}$ & $6(38)^{* *}$ & $1(6)$ & $1(6)$ & $1(6)$ & $0(0)$ \\
\hline \multicolumn{8}{|c|}{ Reported killing of predators by farmers } \\
\hline Before dog & All $(67)^{2}$ & $21(31)^{\star}$ & $19(28)$ & $4(6)$ & $4(6)$ & $1(2)$ & \\
\hline Since dog & All $(67)^{2}$ & $12(18)^{*}$ & $12(18)$ & $0(0)$ & $2(3)$ & $0(0)$ & \\
\hline Before dog & Commercial (47) & $15(32)$ & $13(28)$ & $3(6)$ & $4(9)$ & $0(0)$ & \\
\hline Since dog & Commercial (47) & $12(26)$ & $12(26)$ & $0(0)$ & $2(4)$ & $0(0)$ & \\
\hline Before dog & Subsistence (20) & $6(30)^{*}$ & $6(30)^{*}$ & $1(5)$ & $0(0)$ & $1(5)$ & \\
\hline Since dog & Subsistence (20) & $0(0)^{\star}$ & $0(0)^{\star}$ & $0(0)$ & $0(0)$ & $0(0)$ & \\
\hline
\end{tabular}

${ }^{1}$ Of the original sample of 83 , four dogs working with previously placed guarding dogs were excluded, and 19 respondents were uncertain when answering questions about livestock losses.

${ }^{2}$ Of the original sample of 83,10 dogs placed on the same farm as previous guarding dogs were excluded, and six respondents were uncertain when answering questions about killing predators.

${ }^{*} \mathrm{P}<0.05 ;{ }^{* *}, \mathrm{P}<0.01$

TABLE 2 The mean number of predators ( \pm SE) killed by farmers before and since the introduction of livestock guarding dogs.

\begin{tabular}{|c|c|c|c|c|c|}
\hline Status & All predators $(n=62)$ & Jackal $(\mathrm{n}=62)$ & Cheetah $(n=67)$ & Caracal $(n=66)$ & Leopard $(n=67)$ \\
\hline Before dog & $1.8 \pm 0.67^{*}$ & $1.7 \pm 0.65^{*}$ & $0.2 \pm 0.17$ & $0.1 \pm 0.06$ & $0.02 \pm 0.015$ \\
\hline Since dog & $1.2 \pm 0.63^{*}$ & $1.2 \pm 0.63^{*}$ & 0.0 & $0.05 \pm 0.046$ & 0.0 \\
\hline
\end{tabular}

*, $\mathrm{P}<0.05$

farm per year since the dogs were introduced, but this result was not significant $(z=-0.67, \mathrm{P}=0.50, \mathrm{n}=66$; Fig. $2 \mathrm{~b})$. A reverse, yet non-significant, trend was found for the two protected species. Farmers alone killed $0.11 \pm \mathrm{SE} 0.06$ cheetahs before the dogs were introduced, whereas since the dogs were introduced no farmers killed cheetahs and one dog killed one cheetah (0.02 \pm SE 0.02 per farm per year) that had jumped into the night-time livestock enclosure $(z=-1.51, \mathrm{P}=0.13, \mathrm{n}=67$; Fig. $2 \mathrm{c})$. A farmer killed one leopard (0.02 \pm SE 0.02 per farm per year) before the dogs were introduced, and no leopards were killed since the dogs were introduced $(z=-1.00, \mathrm{P}=0.32, \mathrm{n}=67)$.

\section{Livestock guarding dogs and non-target species}

Two guarding dogs $(n=79)$ killed non-target carnivore species; one killed a single bat-eared fox Otocyon megalotis and the other an unknown number of African wildcat Felis silvestris. Both of these dogs also killed predators that can threaten sheep and goats (one killed a baboon, the other a jackal and a caracal).
Eight dogs (10\%) killed less valuable prey (0.1 \pm SE 0.05 killed, $n=77)$, and eight dogs $(10 \%)$ killed more valuable prey ( $0.2 \pm$ SE 0.08 killed, $n=79$ ). Reportedly only calves of the more valuable prey species (eland Tragelaphus oryx, kudu Tragelaphus strepsiceros and oryx Oryx gazella) were killed by these dogs. One dog killed both types of prey species. Thirteen of the 15 dogs reported to kill prey species also killed target predator species.

\section{Discussion}

Livestock guarding dogs and target predators

In broad terms the presence of livestock guarding dogs reduced the number of farmers reporting livestock losses to predators, and killing target predator species. Although subsistence farmers ceased killing predators after receiving their dogs, $26 \%$ of the commercial farmers continued to kill predators during the survey year. This result differs from studies in other African countries, which reported that commercial farmers expressed more positive attitudes than 

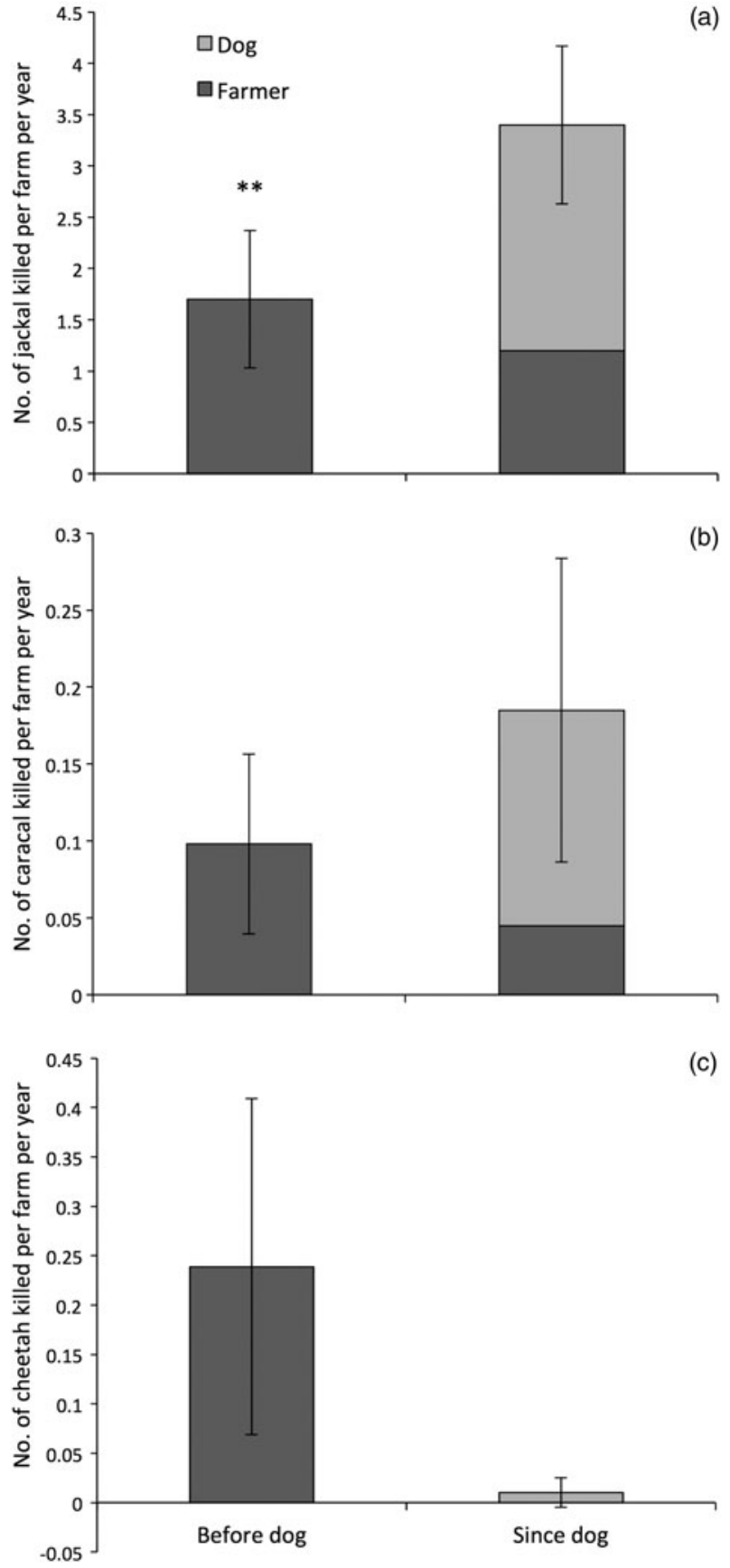

FIG. 2 Numbers of jackal Canis mesomelas (a), caracal Caracal caracal (b) and cheetah Acinonyx jubatus (c) killed per farm per year, before and since the introduction of livestock guarding dogs on farms in Namibia (Fig. 1). ${ }^{\star *}$ indicates a significant difference at $\mathrm{P}<0.01$; error bars show $\pm \mathrm{SE}$.

subsistence farmers towards predators (Romañach et al., 2007; Selebatso et al., 2008). However, our study included a relatively small number of subsistence farmers. The 20 subsistence farmers relied entirely on the dogs to control predators, perhaps because they had limited resources for predator control. In Namibia and South Africa commercial farmers appear to be driven more by their perceptions of predators than actual livestock losses (Marker et al., 2003; Thorn et al., 2015). Consequently, introducing livestock guarding dogs should be part of a larger strategy to engage commercial livestock farmers to reduce killing of predators in this region.

By considering only 1 year before and 1 year after the introduction of livestock guarding dogs our study only provided a snapshot of the predator control methods used by responding farmers. Given the extensive placement of dogs in our study (Fig. 1), objective information on trends in predator populations on target farms was lacking. More intensive studies using data from multiple years before and after the introduction of dogs, including concurrent studies on predator populations, would provide a more complete picture.

The high level of tolerance found in this study among farmers for damage-causing predators is not necessarily representative of the overall level of tolerance in Namibia, which was reported to be lower in a previous study (Marker et al., 2003). The farmers in the guarding dog programme represent a subset of farmers in the country (i.e. those that request assistance from carnivore conservation organizations). Consequently the results from the relatively predator-friendly farmers in this study must be applied with caution to the broader livestock farming community.

The reports of guarding dogs killing non-protected predator species challenge the portrayal of these dogs as non-lethal predator control, particularly for medium-sized predators (jackal and caracal in our study area). The net result of dog introduction was a significant increase in the killing of jackals, and a non-significant reduction in the killing of protected, larger-bodied predators (leopard and cheetah).

Our data relied on the honesty and recollection of the respondents, as the wide geographical distribution and number of dogs precluded independent monitoring. However, the widespread, independent reports of dogs killing predators (particularly jackals) presented here indicate that guarding dogs kill medium-sized predators more regularly than previously reported. Intensive monitoring of guarding dogs would be required to produce a more reliable estimate of numbers of predators killed, and to determine if guarding dogs selectively kill jackals that approach the livestock. The use of guarding dogs could thus be compared with other selective lethal control methods that target relatively abundant mesopredators.

In 2010 there was a spike in the incidence of rabies among domestic dogs in Namibia (Hassel, 2013), suggesting an increase in rabid jackals in the study year. Rabid jackals are likely to be unnaturally aggressive and fearless, which may make them more vulnerable to killing by guarding dogs than healthy jackals. However, none of the farmers in our study reported potential rabies infection in their guarding dogs, and eyewitness accounts of dogs killing jackals suggested that the jackals behaved normally. 
A previous study involving Namibian farmers showed a link between farmers perceiving the jackal as a problem species and perceiving the cheetah as a problem species (Marker et al., 2003). Introducing guarding dogs on Namibian farms where jackal and cheetah are reported to cause livestock losses may therefore increase farmers' tolerance of cheetahs by preventing livestock depredation and selectively killing jackals. Large-bodied apex predators such as cheetah and leopard are more threatened by retaliatory killing by farmers (Woodroffe \& Ginsberg, 1998; Cardillo et al., 2004; Kissui, 2008) than mesopredators such as jackal and caracal, which are resilient to persecution (Inskip \& Zimmermann, 2009; Thorn et al., 2015). Livestock guarding dogs therefore remain an important means of mitigating conflict between Namibian farmers and large carnivores, as in other countries (Urbigkit \& Urbigkit, 2010; Lescureux \& Linnell, 2014). However, large-breed guarding dogs must be used with caution in areas where smaller carnivores are threatened.

\section{Livestock guarding dogs and non-target species}

Only two of the guarding dogs in this study $(\mathrm{n}=79)$ were reported to kill non-target carnivore species. The relatively low impact of these dogs on non-target carnivores should be compared to that of other lethal control methods that the dogs may replace. A quantitative, comparative study is required to determine whether guarding dogs are more species specific than other lethal control methods.

The prevalence of guarding dogs reportedly killing prey species (18\%) in this study was lower than the prevalence of guarding dogs chasing wildlife (46\%) reported early in the Cheetah Conservation Fund's dog programme (Marker et al., 2005). Previous analyses of guarding dogs in this programme have found that wildlife-chasing behaviour is not linked to the age of the dog or the care provided by the farmer (Potgieter, 2011). Additionally, wildlife-chasing behaviour appears to be declining among dogs in the programme, as farmers are advised on dog-training techniques to correct this behaviour (Potgieter, 2011).

The numbers of animals reportedly killed by guarding dogs were relatively small. However, these figures represent minimum numbers killed, as we relied on respondents witnessing their dogs killing wildlife. On farms where the dogs did not work with herders, wildlife killings may have gone unnoticed by farmers. Dogs chasing and/or killing wildlife remains a concern, as the disturbance caused by the dogs will adversely affect prey populations, even if lethal encounters are rare (Gingold et al., 2009; Cromsigt et al., 2013). Guarding dogs used under less controlled conditions than those in our study could have a greater impact on prey populations; dogs used under such conditions must therefore be monitored, and their negative impacts reduced where possible.
We have shown that livestock guarding dogs in Namibia cannot be considered a non-lethal means of predator control, particularly with respect to medium-sized carnivores. However, as reported previously, we suggest that introducing guarding dogs may increase farmers' tolerance of larger carnivores such as the cheetah. Finally, some guarding dogs reportedly kill non-target species. Training farmers and herders to correct wildlife-chasing behaviour in guarding dogs thus remains essential. These factors should be considered carefully when introducing livestock guarding dogs to mitigate farmer-carnivore conflict.

\section{Acknowledgements}

We thank the staff and volunteers at the Cheetah Conservation Fund for their assistance with the livestock guarding dog programme. In particular, we thank Gephardt Nikanor for assisting with data collection, and Matti Nghikembua for assistance with the map. Dr Anne Schmidt-Küntzel provided many helpful suggestions.

\section{References}

Balme, G.A., Slotow, R. \& Hunter, L.T.B. (2009) Impact of conservation interventions on the dynamics and persistence of a persecuted leopard (Panthera pardus) population. Biological Conservation, 142, 2681-269o.

Bangs, E., Jimenez, M., Niemeyer, C., Fontaine, J., Collinge, M., Krsichke, R. et al. (2006) Non-lethal and lethal tools to manage wolf-livestock conflict in the northwestern United States. In Proceedings of the 22nd Vertebrate Pest Conference (eds R.M. Timm \& J.M. O'Brien), pp. 7-16. University of California, Davis, USA.

Breitenmoser, U., Angst, C., Landry, J.-M., Breitenmoser-Würsten, C., Linnell, J.D.C. \& Weber, J.-M. (2005) Non-lethal techniques for reducing depredation. In People and Wildlife: Conflict or Coexistence? (eds R. Woodroffe, S. Thirgood \& A. Rabinowitz), pp. 49-61. Cambridge University Press, Cambridge, UK.

Cardillo, M., Purvis, A., Sechrest, W., Gittleman, J.L., Bielby, J. \& MACE, G.M. (2004) Human population density and extinction risk in the world's carnivores. PLoS Biology, 2(7), e197.

Cromsigt, J.P.G.M., Kuijper, D.P.J., Adam, M., Beschta, R.L., Churski, M., Eycott, A. et al. (2013) Hunting for fear: innovating management of human-wildlife conflicts. Journal of Applied Ecology, 50, 544-549.

Dawydiak, O. \& Sims, D.E. (2004) Livestock Protection Dogs: Selection, Care and Training, 2nd edition. Alpine Publications, Loveland, USA.

Gehring, T.M., Hawley, J.E., Davidson, S.J., Rossler, S.T., Cellar, A.C., Schultz, R.N. et al. (2006) Are viable non-lethal management tools available for reducing wolf-human conflict? Preliminary results from field experiments. In Proceedings of the 22nd Vertebrate Pest Conference (eds R.M. Timm \& J.M. O’Brien), pp. 2-6. University of California, Davis, USA.

Gehring, T.M., VerCauteren, K.C. \& Landry, J.-M. (2010) Livestock protection dogs in the 21st century: is an ancient tool relevant to modern conservation challenges? BioScience, 6o, 299-308. 
Gingold, G., Yom-Tov, Y., Kronfeld-Schor, N. \& Geffen, E. (2009) Effect of guard dogs on the behaviour and reproduction of gazelles in cattle enclosures on the Golan Heights. Animal Conservation, 12, 155-162.

Hassel, R. (2013) Rabies in Namibia with special reference to rabies in kudu antelope (Tragelaphus strepsiceros). Historical background of the disease and project proposal for the development of an oral vaccination method. In Proceedings of the Annual Scientific Veterinary Association of Namibia Congress 2013, pp. 1-22. Veterinary Association of Namibia, Windhoek, Namibia.

Hunter, L.T.B. \& Barrett, P. (2011) A Field Guide to the Carnivores of the World. New Holland Publishers, London, UK.

Inskip, C. \& ZimmermanN, A. (2009) Human-felid conflict: a review of patterns and priorities worldwide. Oryx, 43, 18-34.

KIssuI, B.M. (2008) Livestock predation by lions, leopards, spotted hyenas, and their vulnerability to retaliatory killing in the Maasai steppe, Tanzania. Animal Conservation, 11, 422-432.

LesCuREux, N. \& Linnell, J.D.C. (2014) Warring brothers: the complex interactions between wolves (Canis lupus) and dogs (Canis familiaris) in a conservation context. Biological Conservation, 171, 232-245.

Lorenz, J.R. \& Coppinger, L. (1996) Raising and Training a Livestock-guarding Dog. Oregon State University Extension Service, Corvallis, USA.

Madden, F. \& McQuinn, B. (2014) Conservation's blind spot: the case for conflict transformation in wildlife conservation. Biological Conservation, 178, 97-106.

Marker, L.L., Dickman, A.J. \& Macdonald, D.W. (2005) Perceived effectiveness of livestock-guarding dogs placed on Namibian farms. Rangeland Ecology \& Management, 58, 329-336.

Marker, L.L., Mills, M.G.L. \& Macdonald, D.W. (2003) Factors influencing perceptions of conflict and tolerance toward cheetahs on Namibian farmlands. Conservation Biology, 17, 1290-1298.

Marker-Kraus, L.L., Kraus, D., Barnett, D. \& Hurlbut, S. (1996) Cheetah Survival on Namibian Farmlands, 1st edition. Cheetah Conservation Fund, Windhoek, Namibia.

McManus, J.S., Dickman, A.J., Gaynor, D., Smuts, B.H. \& Macdonald, D.W. (2014) Dead or alive? Comparing costs and benefits of lethal and non-lethal human-wildlife conflict mitigation on livestock farms. Oryx. Http://dx.doi.org/10.1017/ So030605313001610

Miller, B., Dugelby, B., Foreman, D., Martinez del Rio, C. Noss, R., Phillips, M. et al. (2001) The importance of large carnivores to healthy ecosystems. Endangered Species UPDATE, 18 , 202-210.

Ministry of Environment and Tourism (1975) Nature Conservation Ordinance No. 4 of 1975. Http://www.environmentnamibia.net/tl_files/pdf_documents/legal/acts/Nature\%2oConservation \%20Ordinance\%20No\%204\%20of\%201974.pdf [accessed 27 February 2015].

Naidoo, R., Stuart-hill, G., Weaver, L.C., Tagg, J., Davis, A. \& Davidson, A. (2010) Effect of diversity of large wildlife species on financial benefits to local communities in northwest Namibia. Environmental and Resource Economics, 48, 321-335.

Odendanl, W. (2005) Our Land We Farm: An Analysis of the Namibian Commercial Agricultural Land Reform Process. Legal Assistance Centre, Windhoek, Namibia.

PotGieter, G.C. (2011) The effectiveness of livestock guarding dogs for livestock production and conservation in Namibia. MSc thesis. Nelson Mandela Metropolitan University, Port Elizabeth, South Africa.

Potgieter, G.C., Marker, L.L., Avenant, N.L. \& Kerley, G.I.H. (2013) Why Namibian farmers are satisfied with the performance of their livestock guarding dogs. Human Dimensions of Wildlife, 18 403-415.

Redpath, S.M., Bhatia, S. \& Young, J. (2015) Tilting at wildlife: reconsidering human-wildlife conflict. Oryx, 49, 222-225.

Richardson, J.A. (1998) Wildlife utilization and biodiversity conservation in Namibia: conflicting or complementary objectives? Biodiversity and Conservation, 7, 549-559.

RigG, R., Findo, S., Wechselberger, M., Gorman, M.L., Sillero-Zubiri, C. \& Macdonald, D.W. (2011) Mitigating carnivore-livestock conflict in Europe: lessons from Slovakia. Oryx, $45,272-280$.

Ripple, W.J., Estes, J.A., Beschta, R.L., Wilmers, C.C., Ritchie, E. G., Hebilewhite, M. et al. (2014) Status and ecological effects of the world's largest carnivores. Science, 343, 1241484.

Romañach, S.S., Lindsey, P.A. \& Woodroffe, R. (2007) Determinants of attitudes towards predators in central Kenya and suggestions for increasing tolerance in livestock dominated landscapes. Oryx, 41, 185-195.

Selebatso, M., Moe, S.R. \& Swenson, J.E. (2008) Do farmers support cheetah Acinonyx jubatus conservation in Botswana despite livestock depredation? Oryx, 42, 430-436.

Sepúlveda, M.A., Singer, R.S., Silva-Rodríguez, E.A., Stowhas, P. \& Pelican, K. (2014) Domestic dogs in rural communities around protected areas: conservation problem or conflict solution? PLoS ONE, 9(1), e86152.

SHIVIK, J.A. (2006) Tools for the edge: what's new for conserving carnivores. BioScience, 56, 253-259.

Sillero-Zubiri, C. \& Laurenson, M.K. (2001) Interactions between carnivores and local communities: conflict or co-existence? In Carnivore Conservation (eds J.L. Gittleman, S.M. Funk, D.W. Macdonald \& R.K. Wayne), pp. 282-312. Cambridge University Press, Cambridge, UK.

Silva-Rodríguez, E.A. \& Sieving, K.E. (2012) Domestic dogs shape the landscape-scale distribution of a threatened forest ungulate. Biological Conservation, 150, 103-110.

Skinner, J.D. \& Chimimba, C.T. (2005) The Mammals of the Southern African Subregion. Cambridge University Press, Cambridge, UK.

Stadler, H. (2006) Historical perspective on the development of problem animal management in the Cape Province. In Prevention is the Cure. Proceedings of a workshop on Holistic Management of Human-Wildlife Conflict in the Agricultural Sector of South Africa (eds B. Daly, H. Davies-Mostert, W. Davies-Mostert, S. Evans, Y. Friedman, N. King et al.), pp. 11-16. Endangered Wildlife Trust, Western Cape, South Africa.

Thorn, M., Green, M., Dalerum, F., Bateman, P.W. \& Scott, D. M. (2012) What drives human-carnivore conflict in the North West Province of South Africa? Biological Conservation, 150, 23-32.

Thorn, M., Green, M., Marnewick, K. \& Scott, D.M. (2015) Determinants of attitudes to carnivores: implications for mitigating human-carnivore conflict on South African farmland. Oryx, 49, 270-277.

Treves, A. \& Karanth, K.U. (2003) Human-carnivore conflict and perspectives on carnivore management worldwide. Conservation Biology, 17, 1491-1499.

Treves, A. \& Naughton-Treves, L. (2005) Evaluating lethal control in the management of human-wildlife conflict. In People and Wildife: Conflict or Coexistence? (eds R. Woodroffe, S. Thirgood \& A. Rabinowitz), pp. 86-106. Cambridge University Press, Cambridge, UK.

Urbigkit, C. \& Urbigkit, J. (2010) A review: the use of livestock protection dogs in association with large carnivores in the Rocky Mountains. Sheep \& Goat Research Journal, 25, 1-8. 
van Bommel, L. \& Johnson, C.N. (2012) Good dog! Using livestock guardian dogs to protect livestock from predators in Australia's extensive grazing systems. Wildlife Research, 39, 220-229.

Vanak, A.T. \& Gompper, M.E. (2009) Dogs Canis familiaris as carnivores: their role and function in intraguild competition. Mammal Review, 39, 265-283.

Woodroffe, R. \& Ginsberg, J.R. (1998) Edge effects and the extinction of populations inside protected areas. Science, 280 , 2126-2128

Woodroffe, R., Thirgood, S. \& Rabinowitz, A. (2005) The impact of human-wildlife conflict on human lives and livelihoods. In People and Wildlife: Conflict or Coexistence? (eds R. Woodroffe, S. Thirgood \& A. Rabinowitz), pp. 13-26. Cambridge University Press, Cambridge, UK.

Young, J.K., Olson, K.A., Reading, R.P., Amgalanbaatar, S. \& BERGER, J. (2011) Is wildlife going to the dogs? Impacts of feral and free-roaming dogs on wildlife populations. BioScience, 61, 125-132.

\section{Biographical sketches}

Gail Potgieter specializes in human-wildlife conflict and has worked in Namibia and South Africa for 6 years. Her main research interests are human-predator conflict mitigation, carnivore ecology in human-dominated landscapes, and community-based conservation. GRAHAM KeRLEY's main research interests are resource use by large herbivores and large predators and the conservation biology of large mammals. He is also engaged in governance of conservation organizations. LAURIE MARKER's research has focused on cheetah biology, ecology and conservation strategies, specializing in human-wildlife conflict, habitat restoration and predator-prey interactions. 